\title{
Novel approach to determination of Fe(II) using a flow system with direct-injection detector
}

\author{
Justyna Paluch ${ }^{1} \cdot$ Paweł Kościelniak ${ }^{1} \cdot$ Iwona Molęda ${ }^{1} \cdot$ Karol Machowski $^{1}$ - Sławomir Kalinowski ${ }^{2}$. \\ Stanisława Koronkiewicz ${ }^{2}$ Joanna Kozak ${ }^{1}$
}

Received: 15 April 2020 / Accepted: 16 June 2020 / Published online: 24 July 2020

(c) The Author(s) 2020

\begin{abstract}
This paper presents a novel, automatic, simple approach to stop-flow photometric determination of Fe(II) in wastewater and wine samples using a multi-pumping flow system with a direct-injection detector. The basis for the determination was the reaction of $\mathrm{Fe}(\mathrm{II})$ with 1,10-phenanthroline, which was carried out in the reaction chamber of the direct-injection detector. The research included a selection of appropriate parameters of the proposed analytical procedure and method validation. Under optimized conditions, linear calibration curves were obtained in two concentration ranges of $\mathrm{Fe}$ (II) $0.07-1.00$ and $1.00-7.00 \mathrm{mg} / \mathrm{dm}^{3}$, with the quantification limit of $0.07 \mathrm{mg} / \mathrm{dm}^{3}$. The procedure was validated by studying the accuracy $(8.2 \%, \mathrm{RE})$ and precision $(9.6$ and $14.8 \%, \mathrm{RSD}$, for higher and lower concentration range, respectively). The proposed method was successfully employed in Fe(II) determination in spiked wastewater and wine samples with recovery of 95.8-104.5\%. Using the procedure, time of a single analysis (for three independently measured signals) was about $300 \mathrm{~s}$ and sample and reagent consumptions were 240 and $60 \mathrm{~mm}^{3}$, respectively.
\end{abstract}

\section{Graphic abstract}

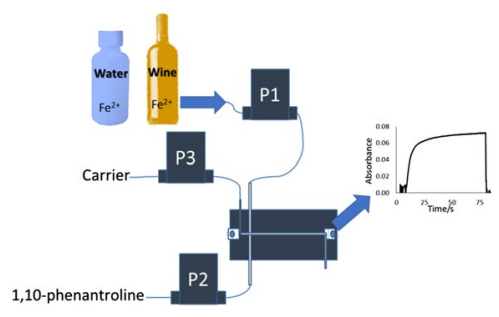

Keywords UV/Vis spectroscopy $\cdot$ Green chemistry $\cdot$ Metals $\cdot$ Flow analysis $\cdot$ Wastewater $\cdot$ Wine samples

\section{Introduction}

The development of flow analysis techniques has created new possibilities for mechanization or automation of analytical procedures. The use of flow systems allows for mechanical insertion and transportation of solutions,

Justyna Paluch

justyna.paluch@uj.edu.pl

1 Faculty of Chemistry, Jagiellonian University, Krakow, Poland

2 Department of Chemistry, University of Warmia and Mazury, Olsztyn, Poland as well as detection in continuous flow conditions. The essence of flow techniques is, however, the possibility of on-line preparation of a sample for analysis through dilution, conducting chemical reactions, preconcentration, or separation of an analyte from the sample matrix using various techniques, like extraction, dialysis, and precipitation. Application of flow techniques often helps improve the precision of analytical results. Moreover, it is consistent with the rules of green analytical chemistry by, among others, reducing the consumption of reagents, and, consequently, the amount of waste produced, increasing the sample throughput, reducing the cost of analyses, as well as limiting the operator's contact with toxic reagents. 
Basic flow analysis techniques include continuous flow analysis (CFA), flow injection analysis (FIA), and sequential injection analysis (SIA). Their numerous modifications were also developed [1,2].

Spectrophotometric determination of $\mathrm{Fe}(\mathrm{II})$ is often based on well-recognized reaction with 1,10-phenanthroline [3-10] or ferrozine [11-18]. Methods based on the formation of $\mathrm{Fe}$ (II) complexes with 2,2'-dipyridylketone picolinoylhydrazone [19] or 2-(5-bromo-2-pyridylazo)-5-(diethylamino)phenol [20, 21] have been also proposed to determine Fe(II) $[19,20]$ or total iron [21]. Fe(II) was also determined after separating Fe species using ion chromatography [3, 22] or liquid/liquid and column solid-phase extraction [23] with flame atomic absorption spectrometry detection, or HPLC method with electrochemical detection [24]. The approaches were applied to the determination of $\mathrm{Fe}$ (II) (also to iron speciation analysis or total iron determination) in water [3, 6-9, $12,14,17,18]$, sea water $[11,12,14,16,18]$, wastewater [13], wine [18-24], acid leachable fractions of sediment and soil [4], and pharmaceutical product [5] samples. Among them several flow-based systems, like flow injection [3-7, 11-13], multisyringe flow injection [21], sequential injection [8], and lab-in-syringe [9], have been reported.

One of the instrumental solutions used in flow techniques involves multi-commutation (MC) [25] and multi-pumping (MP) [26] systems (with electromagnetic valves and/or pumps) coupled with an original direct-injection detector (DID) [27]. In the DID, the sample and the reagent are simultaneously injected (in a countercurrent to ensure proper mixing of solutions) into a reaction chamber, which also serves as a detection chamber. The internal volume of the developed detection-reaction chamber (made of PTFE) was about $60 \mathrm{~mm}^{3}$ (i.d. $2 \mathrm{~mm}$, length $20 \mathrm{~mm}$ ), and two diodes played the roles of the light source and the real detector [27]. The system was adapted to determine Fe(III) in groundwater using the thiocyanate method [28]. The developed approach allowed for determination of $\mathrm{Fe}$ (III) in the concentration range of $0.15-10 \mathrm{mg} / \mathrm{dm}^{3}$ with a relative error (RE) not exceeding $1.5 \%$. The method allowed 180 signals per hour to be recorded. $20 \mathrm{~mm}^{3}$ of both the sample and the reagent was consumed per repetition. The approach was also adapted to chemiluminescent determination of $\mathrm{Fe}$ (III) basing on the Fenton reaction with a reagent containing luminol and $\mathrm{H}_{2} \mathrm{O}_{2}$, enabling determination of $\mathrm{Fe}$ (III) with RE of $2 \%$ [29]. The linear range of the method was in the range of $0.5-10 \mathrm{mg} /$ $\mathrm{dm}^{3}$, while the detection limit was $0.025 \mathrm{mg} / \mathrm{dm}^{3}$. During the analysis, it was possible to record 144 signals per hour.

In this work, the MP DID system was adapted for the first time to determine Fe (II) using 1,10-phenanthroline. Parameters of the proposed analytical procedure were selected and the method was validated. The usefulness of the developed approach was examined by determination of $\mathrm{Fe}(\mathrm{II})$ in wastewater and wine samples.

\section{Results and discussion}

\section{Flow system and procedure}

The solenoid micropump-based flow system with a directinjection (DID) photometric detector equipped with paired emitter-detector diodes (PEDD) applied in determination of $\mathrm{Fe}(\mathrm{II})$ has been schematically shown in Fig. 1. It was composed of three solenoid micropumps (P1-P3) and PEDD direct-injection detector. P1 and P2 with nominal volume of $20 \mathrm{~mm}^{3}$ per pulse were used for injecting the sample and 1,10-phenanthroline, respectively, whereas P3 with nominal volume of $40 \mathrm{~mm}^{3}$ per pulse was used for cleaning DID with water. A special electronic adapter was used to control all the components of the flow system using computer software.

When cleaning, the chamber of DID was filled up with the water stream $\left(400 \mathrm{~mm}^{3}\right)$ using pump P3. Baseline was established in stop-flow mode. Next, $80 \mathrm{~mm}^{3}$ of the sample was injected using pump P1 and then (after 7 s) 20 $\mathrm{mm}^{3}$ of 1,10-phenanthroline was also injected. At that moment, the chemical reaction started and the measurement of absorbance was performed in stop-flow conditions after $70 \mathrm{~s}$.

\section{Optimization of experimental parameters}

The studies were focused on searching for appropriate experimental conditions that would result in obtaining the highest analytical signal with the best precision. These studies included selecting concentration of 1,10-phenanthroline, time of reaction of the sample with

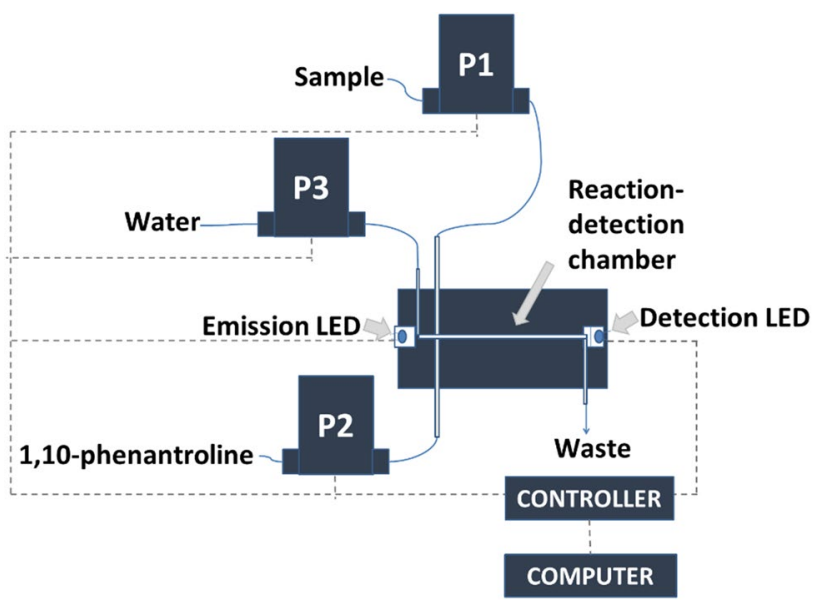

Fig. 1 Scheme of the solenoid micropump-based flow system with direct-injection photometric detector based on paired emitter-detector diodes for determination of $\mathrm{Fe}(\mathrm{II})$; P1-P3 - solenoid micropumps 
1,10-phenanthroline, and volume of sample, based on single-parameter optimization approach. The volume of 1,10-phenanthroline was established for the minimum value possible to inject with the pump used in the system $\left(20 \mathrm{~mm}^{3}\right)$.

Concentration of 1,10-phenanthroline was studied in the range of $0.2-2.0 \%$ by its reaction with $\mathrm{Fe}(\mathrm{II})$ at a concentration of $10 \mathrm{mg} / \mathrm{dm}^{3}$. In the case of 1,10-phenanthroline in concentrations of 1.0 and $2.0 \%$, the precipitate was formed in the solutions after few hours of their preparation that prevented their use for further measurements. The value of $0.5 \%$ was selected as the signal (of the formed compound) reached a plateau much faster for this concentration of 1,10-phenanthroline than it did for $0.2 \%$ (Fig. 2).

Time of reaction of sample with 1,10-phenanthroline was also assessed. With this aim, Fe(II) solution $\left(10 \mathrm{mg} / \mathrm{dm}^{3}\right)$ was introduced into the reaction-detection chamber of DID, followed by the solution of 1,10-phenanthroline $(0.5 \%)$. The signal was registered in stopped-flow mode for $200 \mathrm{~s}$. It was noticed that $70 \mathrm{~s}$ after the reagent injection, the signal practically did not change (Fig. 2). Precision of signals studied for a standard solution containing $\mathrm{Fe}(\mathrm{II})$ at concentration $0.4 \mathrm{mg} / \mathrm{dm}^{3}$ and based on signals registered six times was $9.8 \%$. The choice of time of $70 \mathrm{~s}$ allowed obtain results with acceptable precision in a relatively short time.

To study the sample volume, $\mathrm{Fe}$ (II) solutions of various volumes between 20 and $80 \mathrm{~mm}^{3}$ were tested (Fig. 3). It can be noted that when the volume of sample injected into the DID chamber increased, both improved sensitivity and linearity of the method were observed (see Fig. 3). For volumes (20 and $40 \mathrm{~mm}^{3}$ ) smaller than the DID chamber capacity (60 $\mathrm{mm}^{3}$ ), the sample (after injection) washed part of the water (filling the DID chamber) and it was mixed with the rest of the water. For a volume of $80 \mathrm{~mm}^{3}$, the sample solution

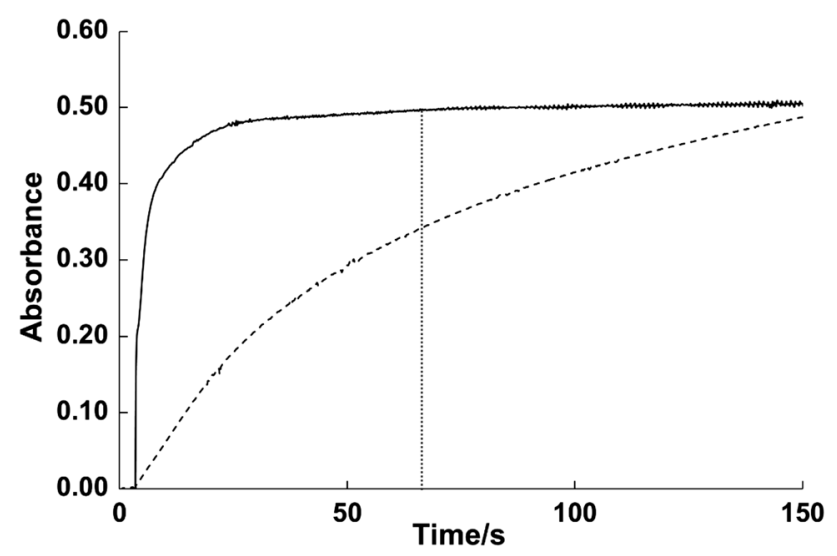

Fig. 2 Signals registered for Fe(II) $\left(10 \mathrm{mg} / \mathrm{dm}^{3}\right)$ with $0.2 \%$ (---) and $0.5 \%$ (- 1,10-phenanthroline injected simultaneously into the DID system; $70 \mathrm{~s}$-time of reaction of sample with 1,10-phenanthroline (an analytical signal measurement)

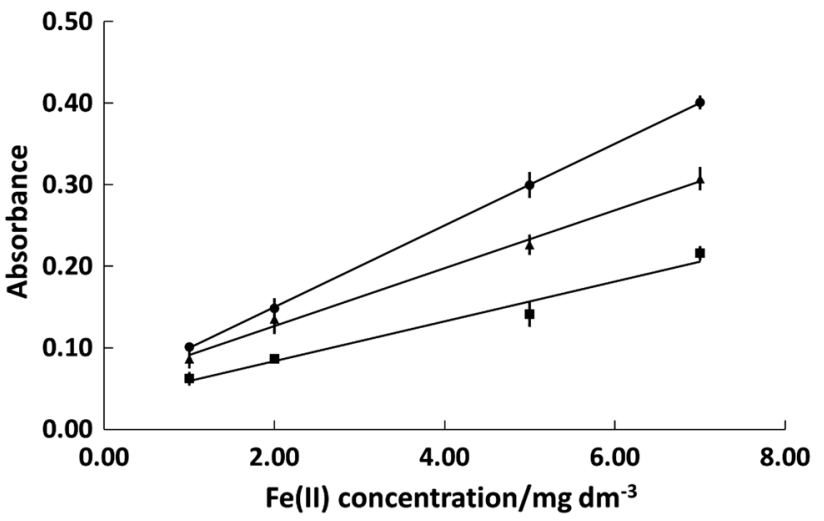

Fig. 3 Influence of sample volume on the slope of calibration graph; filled square $20 \mathrm{~mm}^{3}(A=0.024 c+0.035, R=0.973)$; filled triangle $40 \mathrm{~mm}^{3}(A=0.036 c+0.056, R=0.995)$; and filled circle $80 \mathrm{~mm}^{3}$ ( $A=0.050 c+0.050, R=0.999) ; A$ absorbance, $c$ Fe(II) concentration

washed and replaced water to much more extent (the range of dilution with water was limited); hence, the better sensitivity and linearity of calibration graph were obtained. For this reason, and because of the shorter analysis time and less sample consumption, the introduction of larger volumes was not tested, and a volume of $80 \mathrm{~mm}^{3}$ was used in further studies. Using the developed procedure, time of a single analysis (for three repetitions) was about $300 \mathrm{~s}$ and the sample and reagent consumptions were 240 and $60 \mathrm{~mm}^{3}$, respectively.

\section{Figures of merit of developed approach}

Under the conditions defined above, the main figures of merit of the developed method were studied. The linearity of the calibration graph responsible for $\mathrm{Fe}$ (II) determination was studied in concentration range from 0.05 to $8.00 \mathrm{mg} / \mathrm{dm}^{3}$. A signal for blank was measured and its value was subtracted from the standard signals. It was found that, based on the received signals, two linear calibration graphs $(R=0.999)$ could be prepared for the lower and the higher analyte concentration ranges, from 0.07 to $1.00 \mathrm{mg} / \mathrm{dm}^{3}$ (based on 10 standard solutions, $A=0.051 c+0.013 ; A$-absorbance, c- $\mathrm{Fe}$ (II) concentration) and from 1.00 to $7.00 \mathrm{mg} / \mathrm{dm}^{3}$ (based on eight standard solutions, $A=0.043 c+0.022$ ), respectively.

The limits of detection (LOD) and quantification (LOQ) were estimated with the use of standard solution containing $0.10 \mathrm{mg} / \mathrm{dm}^{3}$ of $\mathrm{Fe}$ (II). They were calculated as concentrations corresponding to the ratio of the signal standard deviation to the slope value and multiplied by 3 and 10, respectively. The values of 0.02 and $0.07 \mathrm{mg} / \mathrm{dm}^{3}$ were obtained for LOD and LOQ, respectively.

Accuracy of the approach was assessed by carrying out determination of $\mathrm{Fe}$ (II) in synthetic samples. A set of synthetic samples containing $\mathrm{Fe}(\mathrm{II})$ at different concentrations 
was prepared and analyzed. Each sample was analyzed three times using the system presented in Fig. 1. The analytical results with calculated values of relative standard deviation (RSD, \%) and relative error (RE, \%) are presented in Table 1.

Generally, it can be concluded that using the developed procedure, $\mathrm{Fe}$ (II) was determined with acceptable accuracy, lower than $8.2 \%$ (RE). Similarly, it can be assumed that results were obtained with acceptable precision lower than $10 \%$ (RSD). However, it should be noted that worse values of RSD were obtained for the results in lower concentration range (the worst, $14.8 \%$, for the lowest $\mathrm{Fe}(\mathrm{II})$ concentration, close to the quantification limit) than in higher range (8.7\%). Figures of merit of the developed procedure are summarized in Table 2.

\section{Determination of $\mathrm{Fe}(\mathrm{II})$ in wastewater and wine samples}

In order to verify the applicability of the developed approach for the determination of $\mathrm{Fe}$ (II) in samples of different matrix, quantification of $\mathrm{Fe}(\mathrm{II})$ was carried out for wastewater certified reference material (CRM) and wine samples, as well as for samples spiked with the analyte.

Iron content is an important parameter for controlling the quality and stability of wine. The level of its concentration in wine depends, among others, on the type of grapes, soil characteristics, environmental conditions, and contamination during the manufacturing process [19, 20]. In airtight conditions, iron exists mostly as Fe(II). However, after aerating wine, dissolved oxygen oxidizes $\mathrm{Fe}$ (II) to $\mathrm{Fe}$ (III), which is responsible for the precipitation of coloring matter (blue

Table 1 Results of determination of Fe(II) in synthetic samples

\begin{tabular}{lllll}
\hline No & \multicolumn{2}{l}{ Fe(II) concentration/mg/dm } & RSD/\% & $\mid \mathrm{RE} / / \%$ \\
\cline { 2 - 3 } & Expected & Found* & & \\
\hline 1 & 0.10 & 0.10 & 14.8 & 0.3 \\
2 & 0.30 & 0.29 & 12.6 & 3.4 \\
3 & 0.40 & 0.41 & 1.5 & 1.2 \\
4 & 0.50 & 0.46 & 4.0 & 7.6 \\
5 & 0.60 & 0.60 & 9.1 & 0.2 \\
6 & 0.70 & 0.72 & 7.4 & 3.0 \\
7 & 0.80 & 0.83 & 5.1 & 3.9 \\
8 & 1.00 & 1.01 & 2.6 & 0.9 \\
9 & 2.00 & 2.16 & 8.7 & 8.2 \\
10 & 3.00 & 3.10 & 4.1 & 2.0 \\
11 & 5.00 & 4.99 & 3.5 & 0.1 \\
12 & 6.00 & 5.69 & 1.3 & 5.2 \\
13 & 7.00 & 7.38 & 4.5 & 5.5 \\
\hline
\end{tabular}

(*mean value, $n=3$ ) using the developed approach, $R E$ percentage relative error $(\mathrm{RE}=(($ found value - expected value $) /$ expected value) $\cdot 100$ )
Table 2 Figures of merit of the developed approach

\begin{tabular}{|c|c|}
\hline Parameter & Value \\
\hline $\mathrm{LOD} / \mathrm{mg} / \mathrm{dm}^{3}$ & 0.02 \\
\hline $\mathrm{LOQ} / \mathrm{mg} / \mathrm{dm}^{3}$ & 0.07 \\
\hline Linear range $\mathrm{I} / \mathrm{mg} / \mathrm{dm}^{3}$ & $0.07-1.00$ \\
\hline Precision, $\mathrm{RSD} / \%$ (for linear range $\mathrm{I})^{\mathrm{a}}$ & 14.8 \\
\hline Linear range $\mathrm{I} / \mathrm{mg} / \mathrm{dm}^{3}$ & $1.00-7.00$ \\
\hline Precision, RSD/\% (for linear range II) ${ }^{\mathrm{b}}$ & 8.7 \\
\hline Accuracy, RE/\% & 8.2 \\
\hline Time for signal registration/s & 70 \\
\hline Sample volume $/ \mathrm{mm}^{3}$ & 80 \\
\hline Reagent volume $/ \mathrm{mm}^{3}$ & 20 \\
\hline
\end{tabular}

${ }^{\mathrm{a}} \mathrm{For} \mathrm{Fe}(\mathrm{II})$ concentration $=0.1 \mathrm{mg} / \mathrm{dm}^{3}$

${ }^{\mathrm{b}} \mathrm{For} \mathrm{Fe}(\mathrm{II})$ concentration $=2.0 \mathrm{mg} / \mathrm{dm}^{3}$

casse) and for the cloudiness in white wines (white casse) [20]. In the cited publications, the Fe(II) concentration varied in the range from 0.16 to 4.89 in white wine [18-20, 22, 23], from 2.49 to 2.55 in rose wine [19], and from 0.79 to 9.32 in red wine $[19,20,22]$ samples.

White and rose wine samples were analyzed. For wastewater and wine samples, the interpolative and extrapolative calibration methods were used, respectively. Six calibration standards or three standard additions were used to prepare calibration graphs, respectively. Samples were analyzed three times and the mean values with confidence intervals (with significance level $\alpha=0.05$ ) were calculated. Results are presented in Table 3. To evaluate the agreement between the obtained and expected concentrations (determined plus spiked concentrations), the values were compared with each other using the Student's $t$ test $(\alpha=0.05)$. It was confirmed that the determined concentrations were consistent with the expected values. The recovery of $\mathrm{Fe}(\mathrm{II})$ in wastewater sample did not exceed $104.5 \%$, whereas in wine samples it ranged from 95.8 to 102.7\%. The low Fe(II) content in the wine samples was

Table 3 Results of determination of Fe(II) in CRM samples of wastewater and wine samples and samples spiked with Fe(II)

\begin{tabular}{llll}
\hline Sample & \multicolumn{2}{l}{ Amount of $\mathrm{Fe}(\mathrm{II}) / \mathrm{mg} / \mathrm{dm}^{3}$} & \multirow{2}{*}{ Recovery $\%$} \\
\cline { 2 - 3 } & Added & Found* & \\
\hline Wastewater & 0.00 & $<\mathrm{LOQ}$ & - \\
& 2.00 & $2.05 \pm 0.14$ & 102.3 \\
\multirow{2}{*}{ Rosé wine } & 4.00 & $4.18 \pm 0.25$ & 104.5 \\
\multirow{2}{*}{ White wine } & 0.00 & $0.38 \pm 0.05$ & - \\
& 0.50 & $0.90 \pm 0.07$ & 102.7 \\
& 0.00 & $0.095 \pm 0.023$ & - \\
\hline
\end{tabular}

(*mean value, $n=3, \alpha=0.05$ ) using the developed approach 
due to the fact that the wine was analyzed several weeks after opening.

It can be concluded that the obtained results confirmed the analytical usefulness of the developed approach and the possibility of its application to determine $\mathrm{Fe}$ (II) in wastewater and white and rose wine samples. It should be also noted that the developed flow system has a chance to be applied to determine Fe(II) in water samples.

Comparing the analytical features of the proposed approach with those of previously developed flow-based methods (Table 4), it can be concluded that linear ranges of the methods are similar, although lower detection limits were achieved in some of the methods described earlier. The disadvantage of the developed approach is the precision, acceptable, but lower than for other developed methods (usually below 5\%, RSD). On the other hand, the advantages of the developed system are low reagent consumption (comparable to the consumption using the SIA system), time of analysis (much shorter than using SIA systems), simplicity, and low costs of the system. Most of the reported systems have been developed for the determination of $\mathrm{Fe}(\mathrm{II})$ and $\mathrm{Fe}$ (III) ions. It should be noted that the proposed system can be also adapted to iron speciation analysis, to $\mathrm{Fe}(\mathrm{III})$ determination using the approaches developed earlier $[28,29]$ or after reduction of Fe(III) to $\mathrm{Fe}(\mathrm{II})$, or as a part of multi-detection system to determine $\mathrm{Fe}(\mathrm{II})$ and total iron using AAS or ICP OES method. The further research is going to be conducted in this direction.

Table 4 Comparison of methods developed for Fe(II) determination

\begin{tabular}{lcll}
\hline Method & $\begin{array}{l}\text { Linearity range/ } \\
\mathrm{mg} / \mathrm{dm}^{3}\end{array}$ & $\begin{array}{l}\mathrm{LOD} / \\
\mathrm{mg} / \mathrm{dm}^{3}\end{array}$ & Reference \\
\hline FIA IC & $0.04-1.00$ & 0.002 & 3 \\
FIA & $0.5-25.0$ & 0.2 & 4 \\
FIA & $0.10-3.00$ & 0.03 & 6 \\
FIA & $0.05-4.00$ & 0.01 & 7 \\
SIA & $0.04-4.00$ & 0.01 & 8 \\
Lab in Syringe & $0.06-4.00$ & 0.02 & 9 \\
FIA & $0.02-5.60$ & 0.003 & 11 \\
FIA & $0.02-0.16$ & 0.007 & 12 \\
R FIA & $0.1-5.0$ & 0.01 & 13 \\
MSFIA & $0.36-5.00$ & 0.11 & 21 \\
MP DID & $0.07-1.00$ & 0.02 & This work \\
& $1.00-7.00$ & & \\
\hline
\end{tabular}

MP DID multi-pumping direct-injection detector, FIA flow injection analysis, $I C$ ion chromatography, $R$ reversed, $M S$ multisyringe

\section{Conclusions}

A novel, automatic, simple, and inexpensive method has been proposed for $\mathrm{Fe}$ (II) determination. The approach is based on the use of a multi-pumping photometric flow system with a direct-injection detector and on the reaction of $\mathrm{Fe}$ (II) with 1,10-phenanthroline carried out in the reaction chamber of the direct-injection detector. The method was validated with acceptable accuracy $(8.2 \%, \mathrm{RE})$ and precision (9.6 and 14.8\%, RSD, for higher and lower concentration ranges, respectively). Good recovery values (95.8-104.5\%) proved that developed method can be used for $\mathrm{Fe}(\mathrm{II})$ determination in wastewater and wine samples. Using the procedure, a sample can be analyzed in short time (about $300 \mathrm{~s}$ ) with low sample and reagent consumptions 240 and $60 \mathrm{~mm}^{3}$, respectively.

It can be also noted that the developed flow system has a chance to be applied to determine Fe(II) in water samples. It could be also adapted to iron speciation analysis.

\section{Experimental}

\section{Reagents and solutions}

A stock standard solution of $\mathrm{Fe}$ (II) was prepared daily, by dissolving $0.176 \mathrm{~g}$ of $\left(\mathrm{NH}_{4}\right)_{2} \mathrm{Fe}\left(\mathrm{SO}_{4}\right)_{2} \cdot 6 \mathrm{H}_{2} \mathrm{O}$ (Chempur, Poland) in $16 \mathrm{~cm}^{3}$ of $\mathrm{H}_{2} \mathrm{SO}_{4}\left(1 \mathrm{~mol} / \mathrm{dm}^{3}\right)$ and bringing it up to $25.0 \mathrm{~cm}^{3}$ with water. The stock solutions were diluted appropriately with water to form intermediate or working standard solutions and synthetic samples. The solutions of 1,10-phenanthroline $(0.2,0.5,1.0$, and $2.0 \%(\mathrm{~m} / \mathrm{V}))$ were prepared by dissolving the appropriate amount of 1,10-phenanthroline monohydrate (Lach-Ner, Czech Republic) in $\mathrm{HCl}\left(0.1 \mathrm{~mol} / \mathrm{dm}^{3}\right)$ in $100.0 \mathrm{~cm}^{3}$ volumetric flask. The hydrochloric and sulfuric acids were prepared by appropriate dilution of $37 \% \mathrm{HCl}$ (Merck, Germany) and $98 \% \mathrm{H}_{2} \mathrm{SO}_{4}$ (Merck, Germany), respectively, with water.

Reagents of analytical grade were used. Substance for preparation of stock standard solution was weighed to the nearest $0.0001 \mathrm{~g}$ on analytical balance (RADWAG, Poland). Deionized water (specific conductance under 0.05 $\mu \mathrm{S} / \mathrm{cm}$ ) obtained from HLP5sp system (Hydrolab, Poland) was used throughout this study.

Certified reference material (CRM) of wastewater (EnviroMAT Wastewater, High (EU-H-3) Lot Number: SC8301825 (SCP SCIENCE, USA)) was diluted in accordance with the instructions with water. Samples of wine obtained at a local shop were put into ultrasonic bath (Sonic 3, Polsonic, Poland) for $10 \mathrm{~min}$ before the analysis. 


\section{Instrumentation}

Three solenoid micropumps (ColeParmer, USA) with nominal volume of 20 and $40 \mathrm{~mm}^{3}$ per pulse were used. The direct-injection (DID) photometric detector based on paired emitter-detector diodes (PEDD) (KSP, Poland) was made from one block of PTFE. The volume of the reaction-detection chamber was about $60 \mathrm{~mm}^{3}, 20 \mathrm{~mm}$ in length and $2 \mathrm{~mm}$ in diameter. Two paired LEDs (Huey Jann Electronic, Taiwan) were placed, one on each end. One LED was used as the light source and other as the light detector. The maximum of the emission spectrum of the LED used as a light source matched the maximum of absorption of the $\mathrm{Fe}(\mathrm{II})-1,10$-phenanthroline complex $\left(\lambda_{\max }=512 \mathrm{~nm}\right)$. As an emission and detection diode, a green LED with $\lambda_{\max }=525 \mathrm{~nm}$ and a yellow-green LED with $\lambda_{\max }=570 \mathrm{~nm}$ (which can detect light of wavelength from 470 to $570 \mathrm{~nm}$ ) were selected, respectively.

PEDD DID was described in detail previously [27]. PTFE tubing i.d. $0.8 \mathrm{~mm}$ (IDEX Health and Science, USA) was used as tubes. A special electronic adapter (KSP, Poland) was used to control all the components of the flow system and to register the signal using computer software.

Acknowledgements The authors are grateful for financial support received from the National Science Centre, Poland (Opus, 2017-2020, Grant No. 2016/23/B/ST4/00789).

Open Access This article is licensed under a Creative Commons Attribution 4.0 International License, which permits use, sharing, adaptation, distribution and reproduction in any medium or format, as long as you give appropriate credit to the original author(s) and the source, provide a link to the Creative Commons licence, and indicate if changes were made. The images or other third party material in this article are included in the article's Creative Commons licence, unless indicated otherwise in a credit line to the material. If material is not included in the article's Creative Commons licence and your intended use is not permitted by statutory regulation or exceeds the permitted use, you will need to obtain permission directly from the copyright holder. To view a copy of this licence, visit http://creativecommons.org/licenses/by/4.0/.

\section{References}

1. Melchert WR, Reis BF, Rocha FRP (2012) Anal Chim Acta 714:8
2. Trojanowicz M (ed) (2008) Advances in flow analysis. Wiley, Weinheim

3. Chen S, Li N, Zhang X, Yang D, Jiang H (2015) Spectrochim Acta Part A Mol Biomol Spectrosc 138:375

4. Kozak L, Niedzielski P, Wachowiak K (2013) Microchem J 110:54

5. Oliveira AF, Nóbrega JA, Fatibello-Filho O (1999) Talanta 49:505

6. Kozak J, Gutowski J, Kozak M, Wieczorek M, Kościelniak P (2010) Anal Chim Acta 668:8

7. Kozak J, Jodłowska N, Kozak M, Kościelniak P (2011) Anal Chim Acta 702:213

8. Kozak J, Paluch J, Węgrzecka A, Kozak M, Wieczorek M, Kochana J, Kościelniak P (2016) Talanta 148:626

9. Paluch J, Kozak J, Wieczorek M, Kozak M, Kochana J, Widurek K, Konieczna M, Kościelniak P (2017) Talanta 171:275

10. Mohamed AA, Shalaby AA (2019) Food Chem 274:360

11. Sarradin PM, Le Bris N, Le Gall C, Rodier P (2005) Talanta 66:1131

12. Giokas DL, Paleologos EK, Karayannis MI (2002) Anal Bioanal Chem 373:237

13. Pascual-Reguera MI, Ortega-Carmona I, Molina-Díaz A (1997) Talanta 44:1793

14. Viollier E, Inglett PW, Hunter K, Roychoudhury AN, Van Cappellen P (2000) Appl Geochem 15:785

15. Thompsen JC, Mottola HA (1984) Anal Chem 56:755

16. King DW, Lin J, Kester DR (1991) Anal Chim Acta 247:125

17. Waterbury RD, Yao W, Byrne RH (1997) Anal Chim Acta 357:99

18. Capitán-Vallvey LF, Arroyo E, Berenguer C, Fernández-Ramos M, Avidad DR (2001) Fresenius J Anal Chem 369:139

19. López-López JA, Albendín G, Arufe MI, Mánuel-Vez MP (2015) J Agric Food Chem 63:4545

20. Ferreira SLC, Ferreira HS, de Jesus RM, Santos JVS, Brandao GC, Souza AS (2007) Anal Chim Acta 602:89

21. Phansi P, Kanchana K, Ferreira SLC, Cerda V (2019) Food Chem 277:261

22. Ajlec R, Stupar J (1989) Analyst 114:137

23. Tasev K, Karadjova I, Arpadjan S, Cvetkovic J, Stafilov T (2006) Food Control 17:484

24. Weber G (1991) Fresenius J Anal Chem 340:161

25. Rocha RP, Reis BF, Zagatto EAG, Lima JLFC, Lapa RAS, Santos JLM (2002) Anal Chim Acta 468:119

26. Lapa RAS, Lima JLSC, Reis BF, Santos JLM, Zagatto EAG (2002) Anal Chim Acta 466:125

27. Koronkiewicz S, Kalinowski S (2011) Talanta 86:436

28. Koronkiewicz S, Kalinowski S (2012) Talanta 96:68

29. Koronkiewicz S, Kalinowski S (2015) Talanta 133:112

Publisher's Note Springer Nature remains neutral with regard to jurisdictional claims in published maps and institutional affiliations. 